\title{
Evolução do peso testicular de cordeiros da raça Santa Inês alimentados com diferentes níveis de energia
}

\author{
[Testicle weight evolution of Santa Inês lambs fed different energy levels]
}

\author{
R.M. Assis ${ }^{1}$, J.R.O. Pérez ${ }^{2}$, J.B. Barreto Filho ${ }^{2}$, O.J. De Paula ${ }^{3}$, T.R.V. Almeida ${ }^{1}$, \\ G.L. Macedo Junior ${ }^{4}$, P.M. França ${ }^{1}$ \\ ${ }^{1}$ Aluna de pós-graduação - UFLA - Lavras, MG \\ ${ }^{2}$ Universidade Federal de Lavras - Lavras, MG \\ ${ }^{3}$ CEFET - Bambuí, MG \\ ${ }^{4}$ Aluno de pós-graduação - EV-UFMG - Belo Horizonte, MG
}

\begin{abstract}
RESUMO
Avaliou-se a evolução do peso testicular de cordeiros Santa Inês, alimentados com diferentes níveis de energia. Foram utilizados 64 cordeiros, distribuídos em quatro tratamentos: A - 8,7\%; B - 17,3\%; C - 26,0\% e D $34,7 \%$ de fibra em detergente neutro (FDN), proveniente da forragem na dieta, determinando a variação no consumo de energia metabolizável. Quatro animais de cada tratamento foram abatidos nas idades prédeterminadas de 43, 83, 123 e 173 dias de idade. Os testículos foram separados dos respectivos epidídimos e pesados separadamente. Os animais que receberam as dietas A e B foram os que apresentaram maior consumo de energia metabolizável $\left(14,11 \mathrm{Mcal} / \mathrm{PV}^{0,75}\right)$, os mais pesados $(18,89 \mathrm{~kg}$ e $17,09 \mathrm{~kg}$, respectivamente) e os de maiores pesos dos testiculos $(62,54 \mathrm{~g}$ e $27,16 \mathrm{~g}$, respectivamente), indicando que o desenvolvimento testicular é altamente dependente do desenvolvimento corporal e da quantidade de energia metabolizável consumida. A predição do peso dos testículos por meio da circunferência escrotal mostrou ser mais eficiente do que por meio da idade e do peso vivo dos animais.
\end{abstract}

Palavras-chave: ovino, nutrição, reprodução, desenvolvimento testicular

\begin{abstract}
The development of the testicule weight of Santa Inês lambs, fed different energy levels, was evaluated. Sixtyfour lambs were distributed in four treatments: $A-8.7 \% ; B-17.3 \% ; C-26.0 \%$ and $D-34.7 \%$ of neutral detergent fiber $(N D F)$ supplied by the diet forage, determining the variation of the metabolizable energy intake. Four animals from each treatment were slaughtered at pre-defined ages of 43 days, 83 days, 123 days and 173 days. After slaughtering, the testicles were separated from the epididimous and individually weighted. The animals fed diets $A$ and $B$ presented higher metabolizable energy intake $\left(14.11 \mathrm{Mcal} / \mathrm{L} \mathrm{W}^{0.75}\right)$, higher live weight (18.89kg and $17.09 \mathrm{~kg}$, respectively) and higher testicules weight (62.54g and $27.16 \mathrm{~g}$, respectively), indicating that the testicular development is highly dependent on the body development and the quantity of metabolizable energy intake. The prediction of the testicules weight by the scrotal circumference showed to be more efficient than the age or the live weight of the animals.
\end{abstract}

Keywords: ovine, nutrition, reproduction, testicle development

\section{INTRODUÇÃO}

Entre os efeitos da nutrição na reprodução, é provável que o balanço energético negativo seja o mais importante fator nutricional ligado à baixa função reprodutiva. A ingestão de volumosos com alto teor de fibra é uma das principais causas de deficiência energética, já que é um fator limitante para o consumo (Pérez e Geraseev, 2002).

O uso de reprodutores com maior desenvolvimento testicular e conseqüentemente com alta capacidade de fecundação é de grande importância para garantir boa eficiência reprodutiva do rebanho (Souza et al., 2002).

Recebido em 4 de maio de 2006 
Desse modo, a busca por indicadores da fertilidade de reprodutores tem sido o alvo de diversos estudos nos últimos anos (Freitas et al., 1991; Moura et al., 1999; Souza et al., 2002; Souza, 2003; Souza et al., 2003).

O peso testicular apresenta alta correlação com a produção de espermatozóides (Amann e Schambacker, 1983). Portanto, sua estimativa é considerada um importante fator de prognóstico em ovinos, permitindo aos produtores a escolha de melhores animais destinados à reprodução.

O presente estudo teve como objetivo avaliar o efeito de diferentes níveis de energia metabolizável consumida sobre a evolução do peso testicular de cordeiros da raça Santa Inês.

\section{MATERIAL E MÉTODOS}

O experimento foi realizado com 64 cordeiros da raça Santa Inês. Aos três dias de idade os cordeiros foram separados de suas mães e passaram a receber substituto do leite de ovelha até o desaleitamento aos 55 dias. O sucedâneo utilizado foi uma mistura de leite de vaca $(92 \%)$ com ovo em pó (8\%), fornecida até os 35 dias de idade. Dos 36 dias de idade até o desaleitamento, foi fornecido leite de vaca puro.

Os cordeiros foram distribuídos em quatro tratamentos: A - 8,7\%; B - 17,3\%; C - 26,01\% e D - 34,68\% de FDN, proveniente da forragem (FDNf) na dieta. Quatro animais de cada tratamento foram abatidos nas idades prédeterminadas de 43 dias, 83 dias, 123 dias e 173 dias.

Os animais foram confinados em baias individuais, onde receberam a dieta sólida duas vezes ao dia, sendo que a primeira refeição continha $60 \%$ do total diário ofertado. As dietas experimentais foram isoprotéicas, balanceadas para atender às exigências nutricionais de cordeiros em crescimento, exceto energia, segundo as recomendações do NRC (Nutrient..., 1985). Os animais receberam quantidades de ração que permitiram uma sobra no cocho de $10 \%$ do total oferecido. Diariamente, as sobras foram coletadas e quantificadas, e a oferta de alimentos ajustada de acordo com o consumo do dia anterior.

A composição bromatológica dos ingredientes das dietas fornecidas e a composição química e energética das dietas ingeridas são apresentadas nas Tab. 1 e 2 , respectivamente.

Ao atingirem a idade de abate preestabelecida, os animais foram pesados e abatidos. Os testículos foram separados dos respectivos epidídimos e pesados separadamente. Para as análises estatísticas, utilizou-se a soma dos pesos dos testículos, direito e esquerdo.

Paralelamente, foram realizados quatro ensaios de digestibilidade das dietas fornecidas, para determinação da energia metabolizável, em diferentes fases de desenvolvimento dos animais, o que ocorreu, em média, aos 69 dias, 105 dias, 137 dias e 161 dias de idade. Quatro animais de cada dieta, alojados em gaiolas metabólicas, foram utilizados nos ensaios de digestibilidade.

O delineamento experimental utilizado foi $\mathrm{em}$ blocos ao acaso (DBC) em um arranjo fatorial $4 \mathrm{x} 4$ (quatro níveis de FDNf na dieta e quatro idades de abate), com quatro repetições por tratamento, sendo cada unidade experimental representada por um animal. Os animais foram distribuídos em blocos de acordo com o peso ao nascimento e os animais de cada bloco distribuídos aleatoriamente nos tratamentos experimentais.

Tabela 1. Composição bromatológica dos ingredientes das dietas fornecidas aos cordeiros, expressa em \% de matéria seca

\begin{tabular}{lcccccc}
\hline Ingredientes & MS & PB & FDN & FDA & Ca & P \\
\hline Feno & 86,70 & 8,11 & 81,15 & 41,42 & 0,73 & 0,43 \\
Milho & 86,77 & 10,56 & 15,28 & 3,78 & 0,06 & 0,31 \\
Farelo de soja & 88,40 & 45,62 & 14,06 & 9,88 & 0,45 & 0,78 \\
Premix $^{1}$ & 94,36 & - & - & - & 23,00 & 9,00 \\
\hline
\end{tabular}

${ }^{\mathrm{T}}$ Composição: cálcio $=230 \mathrm{~g}$, fósforo $=90 \mathrm{~g}$, enxofre $=15 \mathrm{~g}$, magnésio $=20 \mathrm{~g}$, sódio $=48 \mathrm{~g}$, cobalto $=100 \mathrm{mg}$, cobre $=700 \mathrm{mg}$, ferro $=2.000 \mathrm{mg}$, iodo $=80 \mathrm{mg}$, manganês $=1250 \mathrm{mg}$, selênio $=200 \mathrm{mg}$, zinco $=2.700 \mathrm{mg}$, flúor $=900 \mathrm{mg}$, vit. A $=200.000 \mathrm{UI}$, vit. $\mathrm{D} 3=60.000 \mathrm{UI}$, vit. $\mathrm{E}=60 \mathrm{UI}$

$\mathrm{MS}=$ matéria seca, $\mathrm{PB}=$ proteína bruta, $\mathrm{FDN}=$ fibra em detergente neutro, $\mathrm{FDA}=$ fibra em detergente ácido, $\mathrm{Ca}=$ cálcio, $\mathrm{P}=$ fósforo. 
Evolução do peso testicular...

Tabela 2. Composição bromatológica e energética das dietas fornecidas aos cordeiros ${ }^{1}$

\begin{tabular}{lcccc}
\hline Variável & Dieta A & Dieta B & Dieta C & Dieta D \\
\hline PB (\%) & 19,18 & 20,00 & 20,41 & 20,13 \\
FDN (\%) & 21,94 & 29,67 & 37,39 & 39,58 \\
FDA (\%) & 11,07 & 12,88 & 17,39 & 19,01 \\
EM (kcal/g) & 2,96 & 3,55 & 2,93 & 2,67 \\
\hline
\end{tabular}

${ }^{1}$ Determinado em ensaio de digestibilidade.

$\mathrm{PB}=$ proteína bruta, $\mathrm{FDN}=$ fibra em detergente neutro, $\mathrm{FDA}=$ fibra em detergente ácido; $\mathrm{EM}=$ energia metabolizável.

Os dados foram analisados pelos procedimentos REG e GLM do programa SAS (SAS, 1996), e as médias foram comparadas pelo teste Tukey.

\section{RESULTADOS E DISCUSSÃO}

Com o resultado da energia metabolizável de cada dieta fornecida, obtida nos ensaios de digestibilidade, foi possível determinar o consumo médio total de energia metabolizável, por unidade de tamanho metabólico $\left(\mathrm{Mcal} / \mathrm{PV}^{0,75}\right.$ ), durante o período experimental (Tab. 3).
A média geral de consumo de energia metabolizável dos animais que receberam as dietas $\mathrm{A}$ e $\mathrm{B}$ foi maior que a dos animais que receberam as dietas $\mathrm{C}$ e $\mathrm{D}(\mathrm{P}<0,05)$. Isso é atribuído ao fato de as dietas $\mathrm{A}$ e $\mathrm{B}$ terem maior proporção de concentrado em relação ao volumoso, fornecendo aos animais maior quantidade de energia. Possivelmente, as dietas $\mathrm{C}$ e $\mathrm{D}$ por apresentarem níveis de fibra mais elevados limitaram o consumo de energia pelos animais, causando uma regulação física na ingestão de alimentos.

Tabela 3. Consumo de energia metabolizável $\left(\mathrm{Mcal} \mathrm{PV}^{0,75}\right)$ por cordeiros da raça Santa Inês, de acordo com a idade, alimentados com quatro diferentes dietas

\begin{tabular}{cccccc}
\hline $\begin{array}{c}\text { Idade } \\
(\text { dias })\end{array}$ & $\begin{array}{c}\text { Dieta A } \\
(8,67 \% \mathrm{FDNf})\end{array}$ & $\begin{array}{c}\text { Dieta B } \\
(17,34 \% \mathrm{FDNf})\end{array}$ & $\begin{array}{c}\text { Dieta C } \\
(26,01 \% \mathrm{FDNf})\end{array}$ & $\begin{array}{c}\text { Dieta D } \\
(34,68 \% \mathrm{FDNf})\end{array}$ & Média \\
\hline 43 & $6,70 \pm 0,48 \mathrm{Da}$ & $6,57 \pm 0,53 \mathrm{Da}$ & $6,70 \pm 0,61 \mathrm{Da}$ & $6,71 \pm 0,35 \mathrm{Da}$ & $6,67 \pm 0,45 \mathrm{D}$ \\
83 & $11,80 \pm 0,91 \mathrm{Ca}$ & $12,03 \pm 0,90 \mathrm{Ca}$ & $11,29 \pm 1,42 \mathrm{Ca}$ & $9,94 \pm 0,87 \mathrm{Ca}$ & $11,26 \pm 1,26 \mathrm{C}$ \\
123 & $14,40 \pm 1,23 \mathrm{Bab}$ & $15,48 \pm 1,40 \mathrm{Ba}$ & $14,31 \pm 1,03 \mathrm{Bab}$ & $13,61 \pm 0,67 \mathrm{Bb}$ & $14,45 \pm 1,22 \mathrm{~B}$ \\
173 & $23,58 \pm 1,08 \mathrm{Aa}$ & $22,38 \pm 1,54 \mathrm{Aab}$ & $19,56 \pm 1,60 \mathrm{Ab}$ & $18,72 \pm 2,05 \mathrm{Ab}$ & $21,06 \pm 2,51 \mathrm{~A}$ \\
\hline Média & $14,11 \pm 6,39 \mathrm{a}$ & $14,11 \pm 6,01 \mathrm{a}$ & $12,97 \pm 4,95 \mathrm{~b}$ & $12,24 \pm 4,73 \mathrm{~b}$ & \\
\hline
\end{tabular}

Valores seguidos por letras maiúsculas distintas na coluna e minúsculas distintas na linha diferem entre si $(\mathrm{P}<0,05)$ pelo teste Tukey.

A média de consumo de energia metabolizável até 123 dias foi maior $(\mathrm{P}<0,05)$ entre os animais da dieta $\mathrm{B}$ em relação aos da dieta $\mathrm{D}$. Até os 173 dias de idade, o consumo de energia metabolizável foi maior $(\mathrm{P}<0,05)$ entre os animais que consumiram a dieta $\mathrm{A}$ em relação aos que consumiram as dietas $\mathrm{C}$ e D. As médias de consumo de energia metabolizável foram diferentes entre tratamentos $(\mathrm{P}<0,05)$ em todas as idades estudadas. Esse período correspondeu à fase de crescimento rápido e de forma linear. Nesse período, o aumento do tamanho dos órgãos digestivos resultou em maior ingestão dos alimentos a serem digeridos e metabolizados, explicando as diferenças encontradas nos consumos de energia metabolizável.
Na Tab. 4 são apresentados os valores médios de peso vivo dos cordeiros até a idade de abate predeterminada e os respectivos desvios-padrão.

A média geral de peso vivo dos animais que consumiram a dieta $\mathrm{A}$ foi maior $(\mathrm{P}<0,05)$ do que a dos que consumiram a dieta $\mathrm{D}$. Isso é atribuído ao fato de os animais que consumiram a dieta A terem consumido mais energia metabolizável, que resultou em maior crescimento e desenvolvimento. Tal desempenho coincide com os resultados encontrados por Santos et al. (1998), que relataram que os animais alimentados com alto nível de concentrado na dieta ganharam mais peso do que aqueles alimentados com baixo nível de concentrado. 
Tabela 4. Peso vivo (kg) de cordeiros da raça Santa Inês, de acordo com a idade, alimentados com quatro diferentes dietas

\begin{tabular}{cccccc}
\hline $\begin{array}{c}\text { Idade } \\
(\text { dias })\end{array}$ & \multicolumn{1}{c}{$\begin{array}{c}\text { Dieta A } \\
(8,67 \% \text { FDNf })\end{array}$} & $\begin{array}{c}\text { Dieta B } \\
(17,34 \% \mathrm{FDNf})\end{array}$ & \multicolumn{1}{c}{$\begin{array}{c}\text { Dieta C } \\
(26,01 \% \mathrm{FDNf})\end{array}$} & $\begin{array}{c}\text { Dieta D } \\
(34,68 \% \mathrm{FDNf})\end{array}$ & Média \\
\hline 43 & $9,90 \pm 0,74 \mathrm{Ca}$ & $10,28 \pm 1,76 \mathrm{Ca}$ & $11,22 \pm 2,35 \mathrm{Ba}$ & $10,67 \pm 1,14 \mathrm{Ba}$ & $10,52 \pm 1,53 \mathrm{D}$ \\
83 & $17,46 \pm 1,85 \mathrm{Ba}$ & $16,32 \pm 1,43 \mathrm{Bab}$ & $14,10 \pm 2,42 \mathrm{ABab}$ & $12,34 \pm 1,61 \mathrm{Bb}$ & $15,06 \pm 2,64 \mathrm{C}$ \\
123 & $19,40 \pm 5,96 \mathrm{Ba}$ & $17,42 \pm 2,83 \mathrm{Ba}$ & $19,07 \pm 4,20 \mathrm{Aa}$ & $17,89 \pm 4,29 \mathrm{Aa}$ & $18,45 \pm 4,08 \mathrm{~B}$ \\
173 & $28,79 \pm 2,78 \mathrm{Aa}$ & $24,32 \pm 2,24 \mathrm{Aab}$ & $21,74 \pm 5,47 \mathrm{~b}$ & $21,35 \pm 3,91 \mathrm{Ab}$ & $24,05 \pm 4,58 \mathrm{~A}$ \\
\hline Média & $18,89 \pm 7,60 \mathrm{a}$ & $17,09 \pm 5,49 \mathrm{ab}$ & $16,53 \pm 5,46 \mathrm{ab}$ & $15,56 \pm 5,20 \mathrm{~b}$ &
\end{tabular}

Valores seguidos por letras maiúsculas distintas na coluna e minúsculas distintas na linha diferem entre si $(\mathrm{P}<0,05)$ pelo teste Tukey.

$\mathrm{Na}$ Tab. 5 são apresentados os valores médios dos pesos dos testículos e respectivos desvios-padrão.

Souza et al. (2003), ao estudarem os aspectos ligados à reprodução de carneiros da raça Santa Inês, não encontraram diferença significativa nos pesos dos testículos direito e esquerdo. Neste trabalho, as médias referem-se à soma dos dois testículos. A média de peso dos testículos dos animais que consumiram a dieta $\mathrm{A}$ foi maior $(\mathrm{P}<0,05)$ do que quando consumiram as dietas $\mathrm{B}, \mathrm{C}$ e D.

Tabela 5. Pesos dos testículos (g) de cordeiros da raça Santa Inês, de acordo com a idade, alimentados com quatro diferentes dietas

\begin{tabular}{cccccc}
\hline $\begin{array}{c}\text { Idade } \\
\text { dias })\end{array}$ & $\begin{array}{c}\text { Dieta A } \\
(8,67 \% \mathrm{FDNf})\end{array}$ & $\begin{array}{c}\text { Dieta B } \\
(17,34 \% \mathrm{FDNf})\end{array}$ & $\begin{array}{c}\text { Dieta C } \\
(26,01 \% \mathrm{FDNf})\end{array}$ & $\begin{array}{c}\text { Dieta D } \\
(34,68 \% \mathrm{FDNf})\end{array}$ & Média \\
\hline 43 & $3,75 \pm 0,39 \mathrm{Ba}$ & $3,58 \pm 1,27 \mathrm{Ba}$ & $3,84 \pm 1,60 \mathrm{Aa}$ & $3,38 \pm 0,79 \mathrm{Ba}$ & $3,63 \pm 1,01 \mathrm{~B}$ \\
83 & $12,50 \pm 3,68 \mathrm{Ba}$ & $11,75 \pm 4,2 \mathrm{Ba}$ & $9,63 \pm 6,61 \mathrm{Aa}$ & $5,23 \pm 1,86 \mathrm{Ba}$ & $9,77 \pm 4,93 \mathrm{~B}$ \\
123 & $33,63 \pm 32,50 \mathrm{Ba}$ & $14,40 \pm 8,32 \mathrm{Ba}$ & $22,85 \pm 10,97 \mathrm{Aa}$ & $18,70 \pm 12,83 \mathrm{ABa}$ & $22,39 \pm 18,34 \mathrm{~B}$ \\
173 & $200,28 \pm 39,52 \mathrm{Aa}$ & $78,90 \pm 25,50 \mathrm{Ab}$ & $65,40 \pm 59,10 \mathrm{Ab}$ & $41,45 \pm 24,13 \mathrm{Ab}$ & $96,51 \pm 72,65 \mathrm{~A}$ \\
\hline Média & $62,54 \pm 86,01 \mathrm{a}$ & $27,16 \pm 33,42 \mathrm{~b}$ & $25,43 \pm 36,75 \mathrm{~b}$ & $17,19 \pm 19,92 \mathrm{~b}$ & \\
\hline
\end{tabular}

Valores seguidos por letras maiúsculas distintas na coluna e minúsculas distintas na linha diferem entre si $(\mathrm{P}<0,05)$ pelo teste Tukey.

As médias de pesos dos testículos dos animais aos 43, 83 e 123 dias de idade não foram diferentes $(\mathrm{P}>0,05)$ entre as dietas estudadas. Tal comportamento é atribuído ao fato de que até a idade de 43 dias os animais ainda estavam em fase de aleitamento, portanto, a maior parte da energia metabolizável consumida era proveniente da dieta líquida e não da dieta sólida. Assim, nessa idade, o consumo das dietas em estudo era baixo. Como os animais foram desmamados aos 55 dias, aos 83 dias o rúmen, provavelmente, ainda estava se adaptando à dieta sólida, conseqüentemente, deve ter havido consumo inconstante das dietas sólidas. Aos 123 dias, o fato de o peso não ter sido diferente entre os tratamentos, possivelmente, deve-se à alta variação individual observada entre os animais. Também não se deve descartar a possibilidade de que, nessas idades, as exigências de energia para o desenvolvimento do sistema reprodutor sejam ainda bastante baixas.
Aos 173 dias de idade, os animais que consumiram a dieta A apresentaram maior peso dos testículos $(\mathrm{P}<0,05)$ do que aqueles que consumiram as dietas B, C e D. Essa diferença, possivelmente, pode ser atribuída à maior demanda de energia para $\mathrm{o}$ crescimento testicular (Matos et al., 1992) do que nas idades mais jovens, quando o crescimento testicular é mais lento.

Em animais da raça Corriedale mantidos em pasto, o peso do testículo variou de 10 a $41 \mathrm{~g}$ aos 175 dias de idade (Bielli et al., 2001), valores mais baixos que o encontrado no presente estudo, aos 173 dias de idade, no grupo de animais que consumiram a dieta A. Isso evidencia que os animais quando consomem dietas com maiores quantidades de energia disponível apresentam maiores pesos testiculares.

Em animais da raça Suffolk, aos 168 dias de idade, Wrobel, et al. (1995) encontraram peso testicular de $113 \mathrm{~g}$ para cada testículo. Esse valor é maior que o 
peso dos testículos dos animais de 173 dias, mesmo quando consumiram a dieta A $(200,28 \mathrm{~g})$, como também, é mais alto que o peso médio geral dos animais de 173 dias do presente estudo (96,51g) Esse resultado, possivelmente, deve-se ao fato de ser a raça Suffolk de maior porte quando comparada com a raça Santa Inês. Estes achados estão de acordo com Souza (2003), que relatou grandes variações de peso testicular entre diferentes raças, sugerindo que componentes genéticos são importantes na determinação dessa variável.

Os pesos dos testículos em relação ao consumo total de energia metabolizável segundo a dieta consumida são apresentados na Fig. 1 .

A equação de regressão do peso dos testículos em função do consumo de energia metabolizável da dieta $\mathrm{A}$ foi a que apresentou maior coeficiente de determinação, mostrando melhor homogeneidade no peso dos testículos. Nas dietas B, C, D e na média geral das dietas, os coeficientes de determinação foram relativamente baixos. No entanto, essas equações foram significativas, permitindo que se estimasse o peso dos testículos por meio do consumo de energia metabolizável.

$\mathrm{O}$ aumento do peso dos testículos, em função do consumo de energia metabolizável pelos animais que consumiram a dieta A, apresentou comportamento quadrático, evidenciando que nos animais que se alimentaram de dietas com maiores níveis de energia metabolizável, o peso dos testículos aumentou acentuadamente na fase de pré ou durante a puberdade. Isso, possivelmente, permitiu aos animais dessa dieta serem mais precoces em relação à puberdade.

Os pesos dos testículos em relação à idade, de acordo com a dieta consumida, são apresentados na Fig. 2.

À medida que aumenta a idade dos animais, também aumenta o peso dos testículos, já que o desenvolvimento testicular acompanha o desenvolvimento corporal (Abella [198-]). Isso é uma conseqüência da evolução da idade. No entanto, quando os animais consumiram dietas com maior quantidade de concentrado, esse aumento no peso dos testículos aconteceu de forma quadrática, mostrando melhora na utilização da energia metabolizável consumida para o desenvolvimento testicular, o que possivelmente propiciou adiantamento na evolução do sistema reprodutivo e possivelmente no estabelecimento da puberdade.

Os coeficientes de determinação das equações de regressão do peso dos testículos, ajustados em função da idade dos animais, foram maiores quando os animais consumiram as dietas $\mathrm{A}$ e $\mathrm{B}$ do que quando se alimentaram das dietas $\mathrm{C}$ e $\mathrm{D}$, apesar de essas também terem apresentado equações estatisticamente significativas. Os altos coeficientes de determinação, observados nas dietas com maiores níveis de energia metabolizável, indicam que é possível estimar a evolução do peso testicular através da idade em cordeiros mantidos nestas condições alimentares.

Os pesos dos testículos em relação ao peso vivo, segundo a dieta consumida são mostrados na Fig. 3.

As equações de regressão do peso dos testículos em função do peso vivo dos animais alimentados com dietas com maior concentração energética apresentaram altos coeficientes de determinação. Já os animais que tiveram menor consumo de energia apresentaram coeficientes menores embora também tenham sido estatisticamente significativos $(\mathrm{P}<0,05)$.

De maneira geral, as equações de regressão do peso dos testículos, ajustadas em função do peso vivo, apresentaram melhores coeficientes de determinação do que as equações do peso dos testículos, ajustadas em função da idade, mostrando que o peso vivo é melhor parâmetro para se estimar o peso dos testículos do que a idade dos animais.

O aumento no peso dos testículos acompanha o aumento no peso vivo dos animais. $\mathrm{O}$ aumento quadrático no peso dos testículos em função do peso vivo dos animais que consumiram dietas com maior quantidade de concentrado, semelhante ao observado no peso dos testículos, em função do consumo de energia metabolizável, confirma que o desenvolvimento corporal e reprodutivo está altamente associado à maior ingestão de energia metabolizável.

Os pesos dos testículos em relação à circunferência escrotal, segundo a dieta consumida, encontram-se na Fig. 4. 
Assis et al.

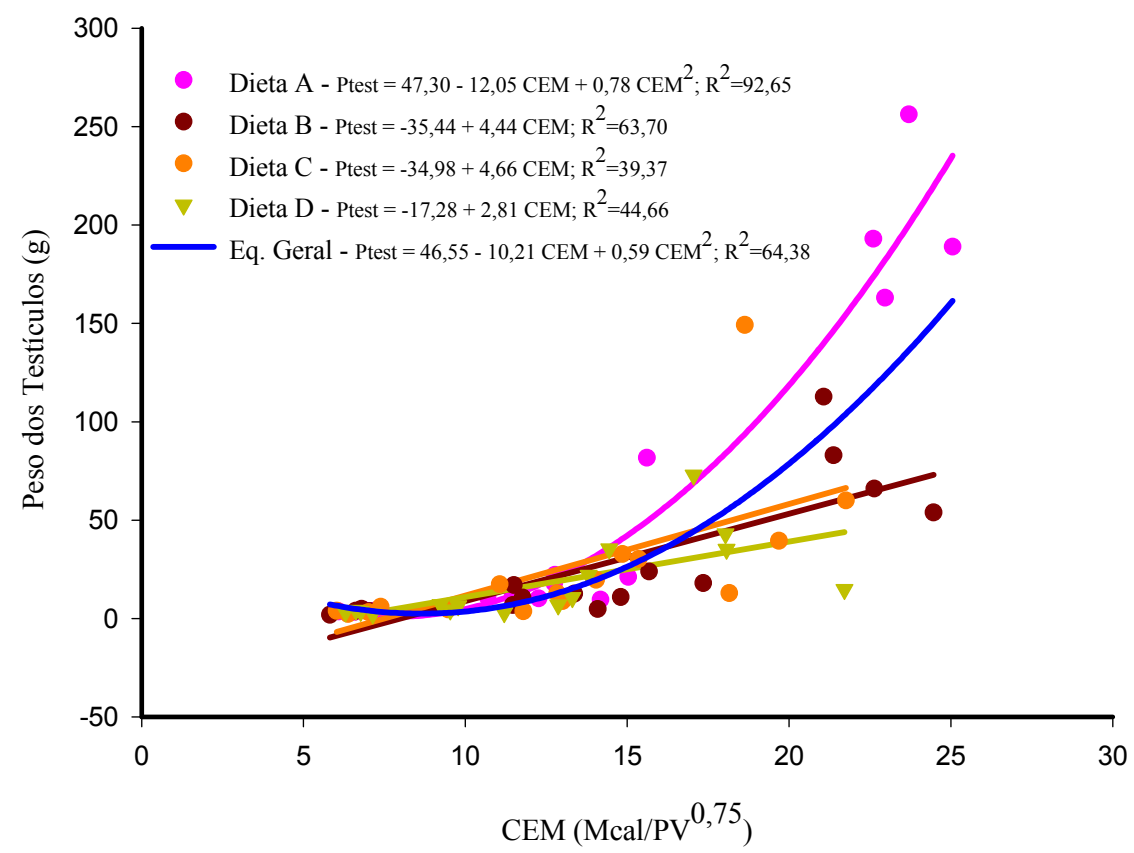

Figura 1. Peso dos testículos em relação ao consumo total de energia metabolizável (CEM) de acordo com dieta consumida por cordeiros da raça Santa Inês em crescimento.

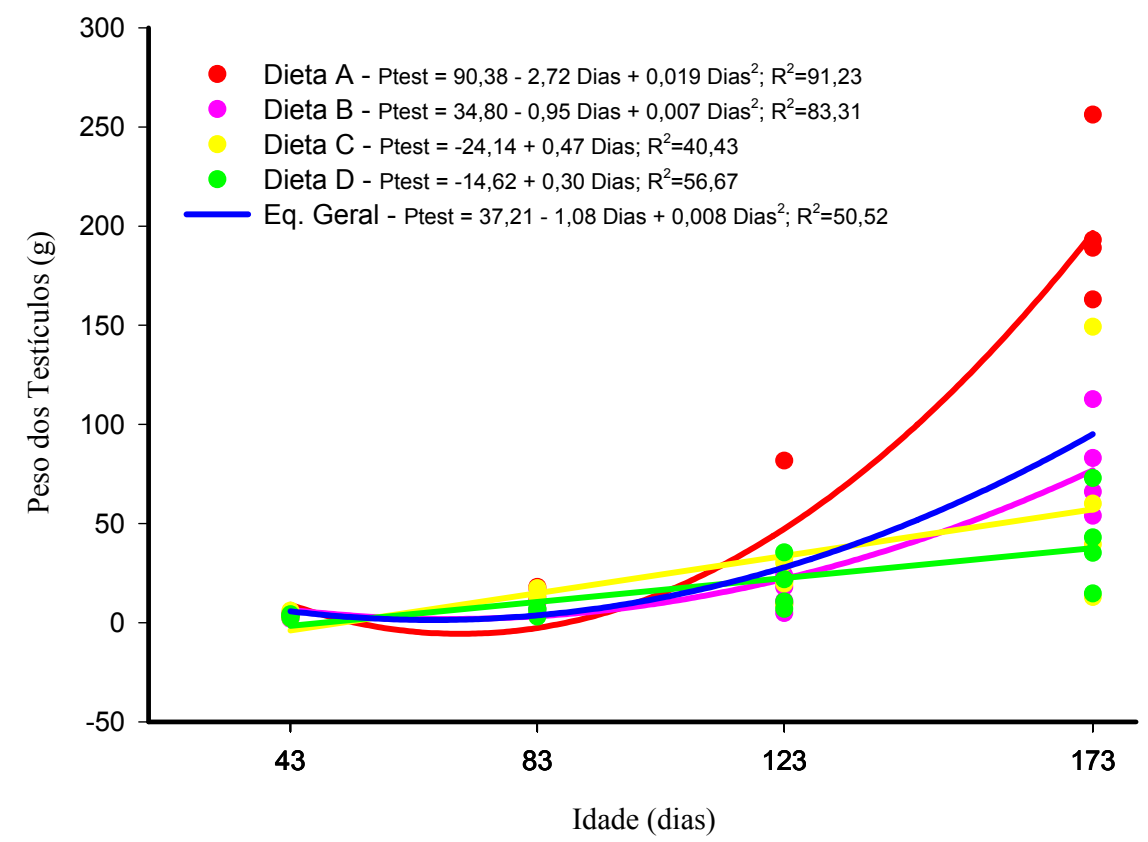

Figura 2. Peso dos testículos em relação à idade, de acordo com a dieta consumida por cordeiros da raça Santa Inês em crescimento. 


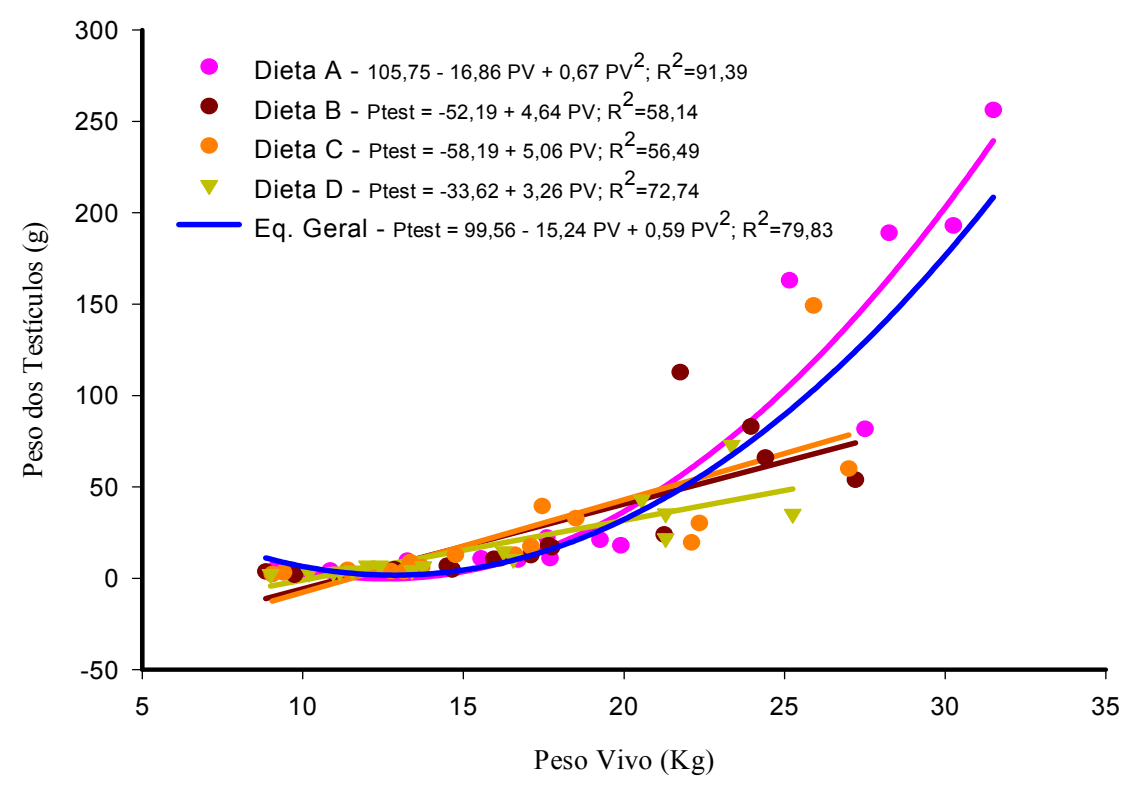

Figura 3. Peso dos testículos em relação ao peso vivo, de acordo com a dieta consumida por cordeiros da raça Santa Inês em crescimento.

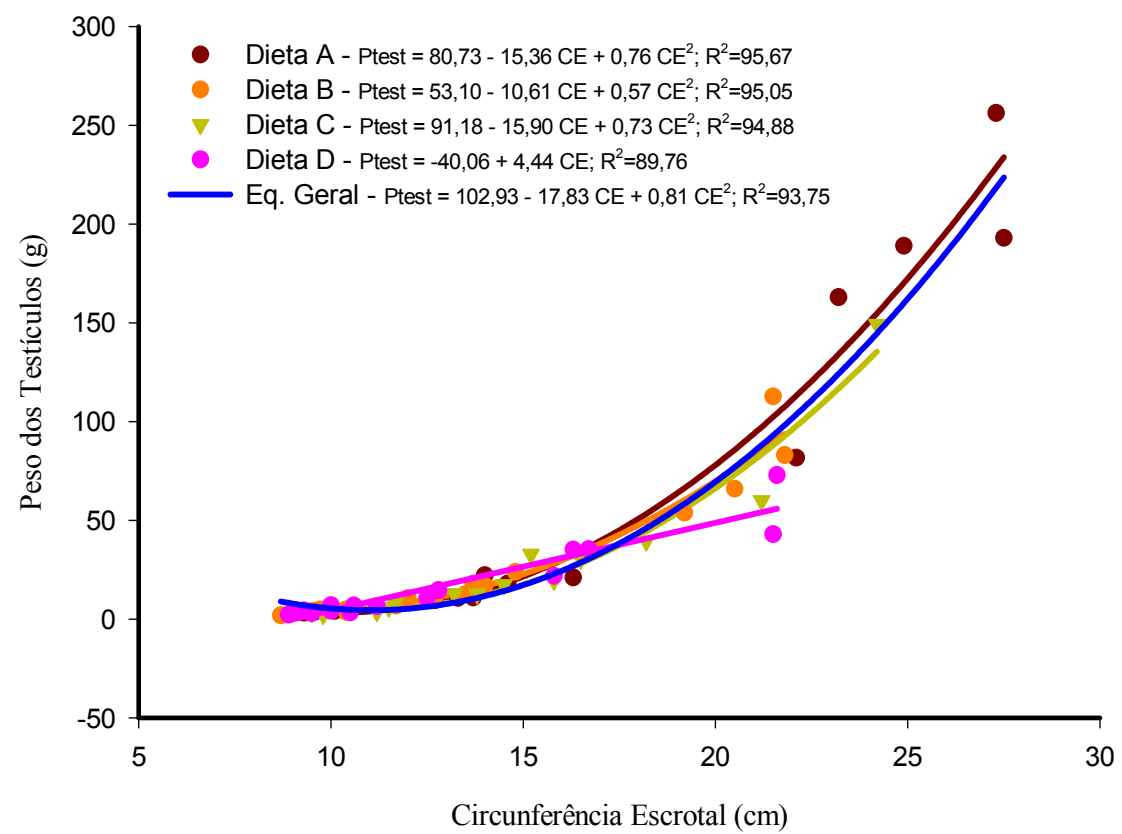

Figura 4. Peso dos testículos em relação à circunferência escrotal de acordo com a dieta consumida por cordeiros da raça Santa Inês em crescimento.

Em todas as dietas estudadas, as equações de regressão do peso dos testículos, ajustadas em função da circunferência escrotal, apresentaram altos coeficientes de determinação. Usando tais equações para predizer o peso dos testículos obtêm-se valores bastante confiáveis, uma vez que tais mensurações são altamente correlacionadas. Isto apresenta a vantagem de se poderem obter informações bastante úteis para a avaliação dos animais quanto à sua capacidade 
reprodutiva. É importante lembrar que a produção diária de espermatozóides em ovinos é estimada em 12 a $25 \times 10^{6}$ espermatozóides por grama de testículo, por dia, o que demonstra claramente a base fisiológica da correlação positiva observada entre o peso dos testículos e a produção espermática (Amann e Schambacker, 1983).

Comparando as equações de regressão do peso dos testículos em função da circunferência escrotal com as equações ajustadas do peso dos testículos, em função do peso vivo e em função da idade, nota-se que a circunferência escrotal como preditor de peso dos testículos apresenta maior precisão, uma vez que os coeficientes de determinação das equações, ajustadas em função do peso vivo e da idade, foram menores em todas as dietas estudadas.

\section{CONCLUSÕES}

Durante a fase de desenvolvimento testicular, animais que consomem maior quantidade de energia apresentam maior peso dos testículos. A predição do peso dos testículos por meio da circunferência escrotal é mais eficiente do que por meio da idade e do peso vivo dos animais.

\section{AGRADECIMENTO}

À FAPEMIG pela concessão de recursos financeiros.

\section{REFERÊNCIAS BIBLIOGRÁFICAS}

ABELLA, D.F. Principios de fisiologia reproductiva ovina. Universidad de la Republica. Editorial Hemisferio Sur, [198-]. 247p.

AMANN, R.P.; SCHAMBACKER, B.D. Phisiology of male reproduction. J. Anim. Sci., v.2, suppl., p.379-403, 1983.

BIELLI, A.; KATZ, H.; PEDRANA, G.; et al. Nutritional management during fetal and postnatal life, and the influence on testicular stereology and sertoli cell numbers in Corriedale rams lambs. Small Rum. Res., v.40, p.63-71, 2001.

FREITAS, V.J.F.; LIMA, F.R.G.; PAIVA, H.M. Biometria testicular de caprinos e ovinos criados no estado do Ceará. Rev. Cien. Anim., v.1, p.51-63, 1991.
MATOS, C.A.P.; THOMAS, D.L.; WALDRON, D.F. et al. Genetic analyses of scrotal circumference size and growth in Rambouillet lambs. J. Anim. Sci., v.70, p.43-50, 1992.

MOURA, A.A.A.; SOUZA, C.E.A.; GARCIA, F.C. de H. et al.. Desenvolvimento ponderal e testicular em carneiros Santa Inês no estado do Ceará. In: REUNIÃO ANUAL DA SOCIEDADE BRASILEIRA DE ZOOTECNIA, 36., 1999, Porto Alegre. Anais... Porto Alegre: SBZ, 1999. CDROOM.

NUTRIENT requirement of sheep. 6.ed. Washington: National Academy, 1985. 99p.

PÉREZ, J.R.O.; GERASEEV, L.C. Exigências de energia, proteína e macrominerais de ovinos. In: OVINOCULTURA: ALGUNS CONCEITOS. Lavras: UFLA, Grupo de Apoio à Ovinocultura, 2002. $152 \mathrm{p}$

SANTOS, M.D; TORRES, C.A.A.; GUIMARÃES, J.D. et al. Sêmen e circunferência escrotal de touros Zebu alimentados com dois níveis de concentrado e lipídeos. Rev. Bras. Zootec., v.27, p.627-632, 1998.

SAS System for windows. Release 6.11, Cary, North Carolina: SAS institute, 1996.

SOUZA, C.E.A. Avaliação da função reprodutiva de carneiros Santa Inês durante o primeiro ano de vida: desenvolvimento testicular, produção espermática e proteínas do plasma seminal. 2003. 160f. Dissertação (Mestrado) - Universidade Federal do Ceará, Fortaleza.

SOUZA, C.E.A.; MOURA, A.A.A.; OLIVEIRA, J.T.A. et al.. Características reprodutivas, concentração de proteínas seminais e testosteronemia de carneiros Santa Inês durante o primeiro ano de vida. In: REUNIÃO REGIONAL DA SBBq - NORDESTE, 6., 2002, Fortaleza, CE. Anais... Fortaleza, 2002. CD ROM

SOUZA, C.E.A.; MOURA, A.A.A.; ARAUJO, A.A. et al. Desenvolvimento puberal de carneiros Santa Inês: desenvolvimento testicular, características seminais e concentrações de testosterona. In: CONGRESSO BRASILEIRO DE REPRODUÇÃO ANIMAL, 15., 2003, Porto Seguro. Anais... Porto Seguro, 2003.

WROBEL, K.H.; REICHOLD, J.; SCHIMMEL, M. Quantitative morphology of the ovine seminifetous epithelium. Ann. Anat. v.177, p.1-14, 1995. 